\title{
Unicompartmental knee arthroplasty and revision total knee arthroplasty have a lower risk of venous thromboembolism disease at 30 days than primary total knee arthroplasty
}

\author{
Andrew M. Schneider ${ }^{*}(\mathbb{D}$, Daniel R. Schmitt and Nicholas M. Brown
}

\begin{abstract}
Background: While multiple studies have demonstrated a lower venous thromboembolism disease (VTED) risk for unicompartmental knee arthroplasty (UKA) compared to primary total knee arthroplasty (TKA), recent reports have shown that revision TKA also had a lower VTED risk compared to primary TKA, an unexpected finding because of its theoretical increased risk. Given the paucity of up-to-date comparative studies, our goal was to perform a highpowered VTED risk comparison study of UKA and revision TKA to primary TKA using recent data.

Methods: The National Surgical Quality Improvement Program (NSQIP) database was queried between 2011 and 2018, and we identified 213,234 patients for inclusion: 191,810 primary TKA, 9294 UKA, and 12,130 revision TKA. Demographics, medical comorbidities, and possible VTE risk factors were collected. Thirty-day outcomes, including deep vein thrombosis (DVT), pulmonary embolism (PE), and all-cause VTED were compared between knee arthroplasty types.

Results: On multivariate analysis, UKA was significantly associated with lower rates of DVT [OR $0.44(0.31-0.61)$; $P<0.001]$, PE [OR $0.42(0.28-0.65) ; P<0.001$, and all-cause VTED [OR $0.42(0.32-0.55) ; P<0.001]$ when compared to primary TKA. Revision TKA was significantly associated with lower rates of PE [OR $0.62(0.47-0.83) ; P=0.002]$, and allcause VTED [OR $0.82(0.70-0.98) ; P=0.029]$ when compared to primary TKA.

Conclusions: Utilizing recent data from a nationwide patient cohort and controlling for confounding variables, our results showed that both revision TKA and UKA had a lower risk of VTED compared to primary TKA, corroborating the results of recent investigations. Additional prospective investigations are needed to explain this unexpected result.
\end{abstract}

Keywords: Total knee arthroplasty, Unicompartmental knee arthroplasty, Venous thromboembolic disease, Revision knee arthroplasty

\footnotetext{
* Correspondence: aschneider2@lumc.edu

Department of Orthopaedic Surgery and Rehabilitation, Loyola University

Medical Center, 2160 S. 1st Ave, Maywood, IL 60153, USA
}

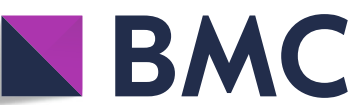

Part of Springer Nature (c) The Author(s). 2020 Open Access This article is licensed under a Creative Commons Attribution 4.0 International License, which permits use, sharing, adaptation, distribution and reproduction in any medium or format, as long as you give appropriate credit to the original author(s) and the source, provide a link to the Creative Commons licence, and indicate if changes were made. The images or other third party material in this article are included in the article's Creative Commons licence, unless indicated otherwise in a credit line to the material. If material is not included in the article's Creative Commons licence and your intended use is not permitted by statutory regulation or exceeds the permitted use, you will need to obtain permission directly from the copyright holder. To view a copy of this licence, visit http://creativecommons.org/licenses/by/4.0/. The Creative Commons Public Domain Dedication waiver (http://creativecommons.org/publicdomain/zero/1.0/) applies to the data made available in this article, unless otherwise stated in a credit line to the data. 


\section{Background}

Venous thromboembolism disease (VTED), which includes both deep vein thrombosis (DVT) and pulmonary embolism (PE), is an inherent risk of lower-extremityjoint arthroplasty [1-3]. Though infrequent, the significant morbidity and mortality associated with VTED make a thorough understanding and mitigation of its risk essential [4-7]. As a result, evidence-based guidelines have been proposed in an effort to limit VTE events, while concurrently minimizing bleeding risk. In the most up-to-date iteration of its guidelines, the American Academy of Orthopaedic Surgeons (AAOS) recommended some form of prophylaxis via pharmacologic agents and/or mechanical compressive devices in patients undergoing hip and knee arthroplasty without an elevated bleeding or VTED risk [8]. However, this recommendation does not discriminate between arthroplasty types, despite differing reported rates and risks of VTED in the literature [9-11].

While there have been numerous studies examining the risk of VTED in primary total knee arthroplasty (TKA), far fewer studies have investigated how that risk compares to other knee arthroplasty procedures, such as unicompartmental knee arthroplasty (UKA) and revision TKA [1, 2, 12-17]. Given the paucity of reliable comparative studies comparing the VTED risk of UKA and revision TKA to primary TKA, we designed a largescale, multivariate analysis using a national database with recent data. We hypothesized that UKA would have less risk of VTED and revision TKA would have greater risk of VTED due to their relative differences in surgical complexity compared to primary TKA.

\section{Methods}

The study population was generated using the American College of Surgeons National Surgical Quality Improvement Program (ACS-NSQIP) database between the years of 2011 and 2018. The NSQIP is a validated outcomes database that reports on surgical outcomes in the 30-day post-operative period, from data gathered by trained surgical clinical reviewers from more than 700 hospitals across the United States. Its data has been found to be generalizable and extremely accurate, with rates of discrepancy $<2 \%$ on random audits $[11,18]$. Inclusion criteria were patients identified using Current Procedural Terminology (CPT) codes 27,447 (arthroplasty knee, condyle and plateau; medial and lateral compartments with or without patellar resurfacing), 27,446 (arthroplasty, knee, condyle and plateau; medial or lateral compartment), and 27,486 and 27,487 (revision of TKA, with or without allograft, one component and revision of TKA, with or without allograft, femoral and entire tibial component, respectively). Exclusion criteria were incomplete patient data, arthroplasty for oncologic indications, and American Society of Anesthesiologists (ASA) class 5 patients. A flow chart demonstrating patient selection can be found in Fig. 1. This study was exempt from Institutional Review Board (IRB) approval because of the de-identified nature of the database.

Demographic variables including age, sex, and body mass index (BMI), as well as comorbidities including diabetes mellitus (DM), smoking status, anesthesia type, and ASA class were recorded for each patient. Operative time was also obtained. This study utilized the available data to determine the risk of DVT, PE, and all combined causes of VTED among the different knee arthroplasty types for the 30-day period following surgical intervention.

\section{Statistical analysis}

The data analysis was completed using SPSS (V26, Armonk, NY, USA). This study conducted univariate analysis by dividing the subjects according to age (18$54,55-75$, and $>75$ years $)$, BMI $(<25,25-35,35-45$, and $>45)$, and operative time $(<2,2-4$, and $>4 \mathrm{~h})$ based on clinically relevant groupings. Univariate analysis was performed using chi-squared tests. Statistical significance was set at a $P$ value $<0.05$. Separate binary multivariate logistic regression models were built using DVT, PE, and all-cause VTED as outcome variables. These models included age, gender, BMI, ASA class, DM history,

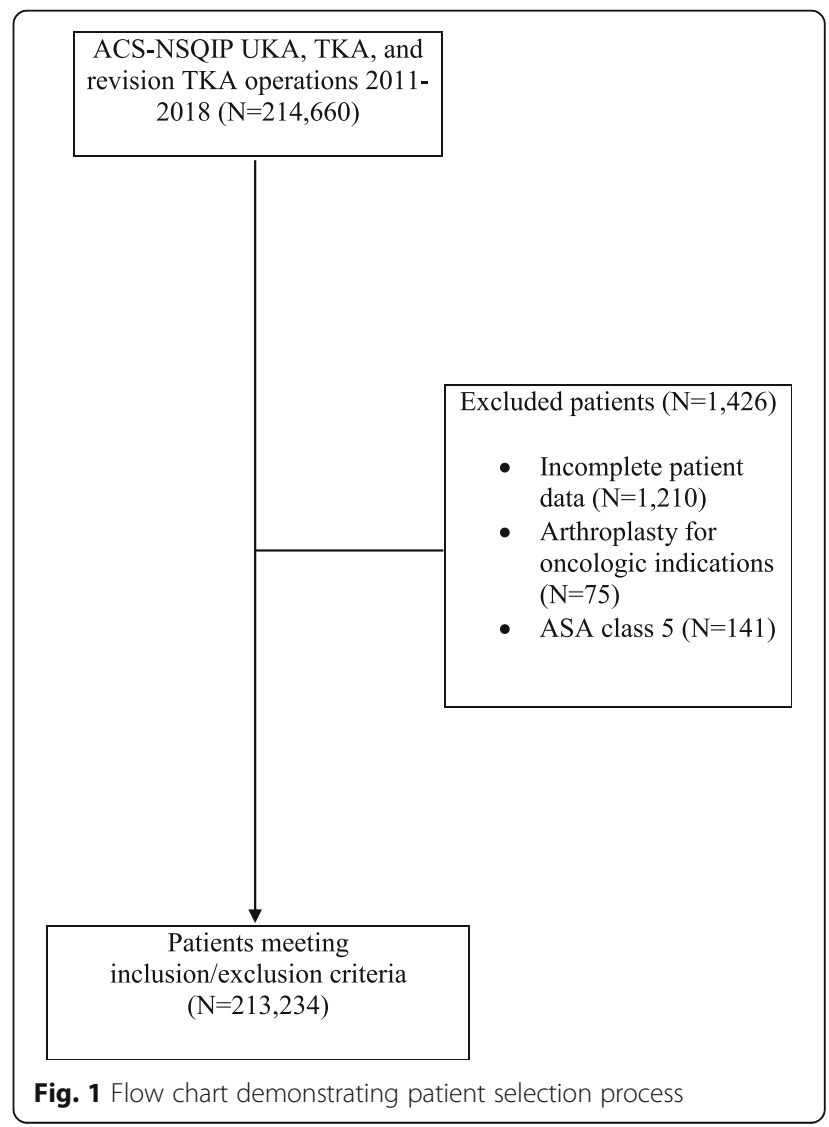


smoking history, anesthesia type, operative time, and type of knee arthroplasty.

\section{Results}

Of the 213,234 patients included in our analysis, 191,810 (90.0\%) underwent primary TKA, 12,130 (5.7\%) underwent revision TKA, and 9294 (4.5\%) underwent UKA.

On univariate analysis (Table 1), older patients had an increased incidence of DVT, PE, and all-cause VTED $(P<$ $0.001)$, while patients with an increased BMI had an increased incidence of PE $(P<0.001)$ and all-cause VTED $(P=0.023)$. More women than men had a PE. General anesthesia $(P=0.003)$ and history of DM $(P=0.016)$ were associated with DVT. Patients undergoing UKA or revision TKA had a decreased incidence of DVT, PE, and all-cause VTE compared to TKA. Neither ASA class nor operative time were associated with DVT, PE, or all-cause VTED.

On multivariate analysis (Table 2), UKA was found to be significantly associated with lower rates of DVT [OR 0.44 (0.31-0.61); $P<0.001$ ], PE [OR $0.42(0.28-0.65)$; $P<0.001$, and all-cause VTED [OR $0.42(0.32-0.55)$; $P<0.001]$ when compared to primary TKA. Additionally, revision TKA was found to be significantly associated with lower rates of PE [OR $0.62(0.47-0.83) ; P=$ 0.002 ], and all-cause VTED [OR $0.82(0.70-0.98) ; P=$ 0.029 ] when compared to primary TKA.

Table 1 Univariate analysis of demographic and comorbidity variables for deep vein thrombosis, pulmonary embolism, and all-cause venous thromboembolic disease

\begin{tabular}{|c|c|c|c|c|c|c|}
\hline & \multicolumn{2}{|l|}{ DVT } & \multicolumn{2}{|l|}{$\mathrm{PE}$} & \multicolumn{2}{|l|}{ VTED } \\
\hline & $N(\%)$ & $P$ value & $\mathrm{N}(\%)$ & $P$ value & $N(\%)$ & $P$ value \\
\hline \multicolumn{7}{|l|}{ Age (years) } \\
\hline $18-54(N=23,636)$ & $192(0.8 \%)$ & $<0.001^{\mathrm{a}}$ & $103(0.4 \%)$ & $<0.001$ & $274(1.2 \%)$ & $<0.001$ \\
\hline $55-75(N=143,972)$ & $1182(0.8 \%)$ & & $815(0.6 \%)$ & & $1858(1.3 \%)$ & \\
\hline$>75(N=45,626)$ & $471(1.0 \%)$ & & $323(0.7 \%)$ & & $722(1.6 \%)$ & \\
\hline \multicolumn{7}{|l|}{ Body mass index $\left(\mathrm{kg} / \mathrm{m}^{2}\right)$} \\
\hline$<25(N=21,699)$ & $189(0.9 \%)$ & 0.101 & $75(0.3 \%)$ & $<0.001$ & $244(1.1 \%)$ & 0.023 \\
\hline $25-34.99(N=119,669)$ & $1083(0.9 \%)$ & & $681(0.6 \%)$ & & $1638(1.4 \%)$ & \\
\hline $35-44.99(N=60,374)$ & $485(0.8 \%)$ & & $419(0.7 \%)$ & & $828(1.4 \%)$ & \\
\hline $45+(N=11,492)$ & $88(0.8 \%)$ & & $66(0.6 \%)$ & & $144(1.3 \%)$ & \\
\hline \multicolumn{7}{|l|}{ Sex } \\
\hline Male $(N=82,759)$ & $743(0.9 \%)$ & 0.203 & $421(0.5 \%)$ & $<0.001$ & $1090(1.3 \%)$ & 0.498 \\
\hline Female $(N=130,475)$ & $1102(0.8 \%)$ & & $820(0.6 \%)$ & & $1764(1.4 \%)$ & \\
\hline History of smoking $(N=18,142)$ & $160(0.9 \%)$ & 0.806 & $897(0.5 \%)$ & 0.062 & $229(1.3 \%)$ & 0.362 \\
\hline History of diabetes mellitus $(N=37,948)$ & $289(0.8 \%)$ & 0.016 & $224(0.6 \%)$ & 0.826 & $486(1.3 \%)$ & 0.290 \\
\hline \multicolumn{7}{|l|}{ Anesthesia type } \\
\hline Regional $(N=107,001)$ & $862(0.8 \%)$ & 0.003 & $641(0.6 \%)$ & 0.319 & $1387(1.3 \%)$ & 0.083 \\
\hline General $(N=105,931)$ & $982(0.9 \%)$ & & $599(0.6 \%)$ & & $1465(1.3 \%)$ & \\
\hline \multicolumn{7}{|l|}{ ASA class } \\
\hline Class $1(N=4231)$ & $40(0.9 \%)$ & 0.337 & $14(0.3 \%)$ & 0.075 & $51(1.2 \%)$ & 0.097 \\
\hline Class $2(N=106,509)$ & $884(0.8 \%)$ & & $600(0.6 \%)$ & & $1366(1.3 \%)$ & \\
\hline Class $3(N=99,006)$ & $892(0.9 \%)$ & & $607(0.6 \%)$ & & $1390(1.4 \%)$ & \\
\hline Class $4(N=3488)$ & $29(0.8 \%)$ & & $20(0.6 \%)$ & & $47(1.3 \%)$ & \\
\hline \multicolumn{7}{|l|}{ Operative time (hours) } \\
\hline$<2(N=172,154)$ & $1467(0.9 \%)$ & 0.406 & $992(0.6 \%)$ & 0.066 & $2270(1.3 \%)$ & 0.117 \\
\hline $2-4(N=33,384)$ & $308(0.9 \%)$ & & $189(0.6 \%)$ & & $463(1.4 \%)$ & \\
\hline$>4(N=7696)$ & $70(0.9 \%)$ & & $60(0.8 \%)$ & & $121(1.6 \%)$ & \\
\hline \multicolumn{7}{|l|}{ Arthroplasty type } \\
\hline Primary total Knee arthroplasty $(N=191,810)$ & $1706(0.9 \%)$ & $<0.001$ & $1169(0.6 \%)$ & $<0.001$ & $2655(1.4 \%)$ & $<0.001$ \\
\hline Unicompartmental knee arthroplasty $(N=9294)$ & $36(0.4 \%)$ & & $22(0.2 \%)$ & & $52(0.6 \%)$ & \\
\hline Revision total knee arthroplasty $(N=12,130)$ & $103(0.8 \%)$ & & $50(0.4 \%)$ & & $147(1.2 \%)$ & \\
\hline
\end{tabular}

${ }^{\mathrm{a} B o l d}$ type signifies statistical significance, $P<0.05$ 
Table 2 Multivariate logistic regression for risk of deep vein thrombosis, pulmonary embolism, and all-cause venous thromboembolic disease among primary total knee arthroplasty, unicompartmental knee arthroplasty, and revision total knee arthroplasty

\begin{tabular}{|c|c|c|c|c|c|c|c|c|c|}
\hline & \multicolumn{3}{|c|}{ Deep vein thrombosis } & \multicolumn{3}{|c|}{ Pulmonary embolism } & \multicolumn{3}{|c|}{ Venous thromboembolic disease } \\
\hline & $\%$ & Odds ratio $(95 \% \mathrm{Cl})$ & $P$ value & $\%$ & Odds ratio $(95 \% \mathrm{Cl})$ & $P$ value & $\%$ & Odds ratio $(95 \% \mathrm{Cl})$ & $P$ value \\
\hline $\begin{array}{l}\text { Primary total knee arthroplasty } \\
(N=191,810)\end{array}$ & 0.9 & Ref. $^{a}$ & - & 0.6 & Ref. & - & 1.4 & Ref. & - \\
\hline $\begin{array}{l}\text { Unicompartmental knee arthroplasty } \\
(N=9294)\end{array}$ & 0.4 & $0.44(0.31-0.61)$ & $<0.001^{\mathrm{a}}$ & 0.2 & $0.42(0.28-0.65)$ & $<0.001$ & 0.6 & $0.42(0.32-0.55)$ & $<0.001$ \\
\hline $\begin{array}{l}\text { Revision total knee arthroplasty } \\
(N=12,130)\end{array}$ & 0.9 & $0.91(0.74-1.12)$ & 0.39 & 0.4 & $0.62(0.47-0.83)$ & 0.002 & 1.2 & $0.82(0.70-0.98)$ & 0.029 \\
\hline
\end{tabular}

Bold type signifies statistical significance, $P<0.05$

${ }^{a}$ Ref. is the baseline reference procedure to which all other procedures are compared

\section{Discussion}

In the current study, we compared the VTED risk of UKA and revision TKA to primary TKA using a highpowered national database with recent data in an effort to corroborate the existing literature on this topic. After controlling for confounding variables, both UKA and revision TKA had a lower risk of VTED compared to primary TKA. Despite advancements in the understanding of perioperative, lower-extremity arthroplasty risks and mitigation practices put forth, serious complications, such as VTED, still occur. Therefore, it is imperative to continually evaluate these risks. Recent reports have consistently shown a lower VTED risk in UKA compared to primary TKA [19-21]. While it has been shown that revision TKA has a higher overall complication risk, including systemic sepsis and deep incisional surgical site infection, there have been few reliable studies using recent data that have investigated the comparative VTED risk of TKA and revision TKA specifically [22].

The lower VTED risk for UKA compared to primary TKA found in our study is supported in the literature. In a report of 423 consecutive UKA patients, Lombardi et al. reported no symptomatic VTED events [14]. In a 2019 study by Hansen et al., over 20,000 UKA and 400, 000 TKA patients were identified in two large nationwide databases and followed for 90 days post surgery [21]. To control for any selection bias, propensity score matching was used on UKA and TKA patients and UKA patients were subsequently found to have a significantly lower risk of both DVT and PE [21]. Brown et al. performed a multi-institutional study looking at the incidence of postoperative complications [23]. Using 2235 primary TKAs and 605 UKAs performed at three institutions over a 5-year period, they found an increased incidence of VTE (1\% vs $0.64 \%$ ) in the TKA group, even after controlling for possible confounding variables, though this result was not statistically significant [23]. The lower VTED risk of UKA compared to TKA was an expected finding of our study. Compared with a primary TKA, a UKA requires less softtissue dissection, less hardware implantation, a shorter operative time, and faster recovery time [21, 24, 25]. Table 3 summarizes the recent literature comparing VTED risk in UKA and primary TKA [19-21, 23].

The lower VTED risk for revision TKA compared to primary TKA found in our study is also supported in the literature. Bohl et al., using NSQIP data from 2011 to 2013, compared adverse events in primary versus revision total hip arthroplasty (THA) and TKA at 30 days post surgery [22]. They found that revision TKA had a lower incidence of both DVT and PE, though the risk was not significantly different from primary TKA. In a retrospective study from 2000 to 2011 of patients taking either aspirin or warfarin for chemoprophylaxis after total joint arthroplasty, Parvizi et al. found that the incidence of symptomatic PE was $1.4 \%$ in revision TKA and $1.8 \%$ in primary TKA [1]. In the only study to our

Table 3 Recent studies on comparative VTED risk between UKA and primary TKA

\begin{tabular}{|c|c|c|c|c|c|c|c|c|c|c|c|}
\hline \multirow[t]{2}{*}{ Study } & \multirow[t]{2}{*}{ Year(s) } & \multirow[t]{2}{*}{ Design } & \multirow[t]{2}{*}{ Follow-up } & \multicolumn{4}{|c|}{ Unicompartmental knee arthroplasty } & \multicolumn{4}{|c|}{ Primary total knee arthroplasty } \\
\hline & & & & $N$ & DVT\% $^{\mathbf{b}}$ & PE\% ${ }^{\mathrm{c}}$ & VTED $\%^{d}$ & $N$ & DVT\% & PE\% & VTED\% \\
\hline Brown & $2004-2009$ & Retrospective & 90 days & 605 & - & - & 0.6 & 2235 & - & - & 1.0 \\
\hline Drager & $2011-2012$ & Retrospective & 30 days & 1340 & 0.5 & $0.0^{\mathrm{a}}$ & - & 36,274 & 0.9 & 0.7 & - \\
\hline Duchman & 2005-2011 & Retrospective & 30 days & 1588 & $0.5^{\mathrm{a}}$ & 0.13 & - & 27,745 & 1.5 & 0.47 & - \\
\hline Hansen & $2002-2012$ & Retrospective & 90 days & 20,488 & $2.04^{\mathrm{a}}$ & $1.56^{\mathrm{a}}$ & - & 415,727 & 3.70 & 3.01 & - \\
\hline
\end{tabular}

DVT deep vein thrombosis, PE pulmonary embolus, TKA total knee arthroplasty, UKA unicompartmental knee arthroplasty, VTED venous thromboembolism disease andicates significant difference compared to corresponding TKA value, $P<0.05$

${ }^{\mathrm{b}}$ Deep vein thrombosis percentage

'Pulmonary embolism percentage

${ }^{\mathrm{d}}$ Venous thromboembolic disease percentage 
knowledge that solely compares revision and primary TKAs, Boylan et al. retrospectively analyzed the New York Statewide Planning and Research Cooperative System (SPARCS), utilizing over 225,000 primary and revision TKAs from 2003 to 2012. They found the 30-day and 90day risk of VTED to be lower for revision TKA than for primary TKA after controlling for age, race, gender, and medical comorbidities [16]. Of note, the data was geographically limited to one state, and smoking status, BMI, and operative time, previously cited risk factors for VTE, were not controlled for [26-28]. The lower VTED risk of revision TKA compared with primary TKA found in our study was not expected. Compared to primary TKAs, revision procedures are typically characterized as more complex. Aspects of revisions such as wider exposures, more softtissue disruption, increased volume and pressurization of cement, instrumentation of the medullary canals, and decreased post-operative mobility all theoretically may lead to an increased risk of VTED [11, 15, 16, 22]. However, reasons for findings to the contrary with respect to revision TKA, both in our study and in the recent literature, are still unclear. Patients with a VTE event during the primary TKA may be less likely to proceed with revision, or they might be put on a more aggressive thromboprophylactic regimen [16]. Additionally, frailer, less functional patients who are more prone to DVT may also be less likely to undergo aseptic revision. Further investigation to better understand this unexpected result is needed. Understanding the results of this study in the context of its limitations is critical. First, it is a retrospective review of a national database that tracks complications, reoperation, and readmission information, making it challenging to understand specific patient characteristics and factors that influence treatment. Moreover, post-operative anticoagulation regimens and overall patient mobility, including physical therapy protocols, are not elucidated in the database. Revision TKA is a very heterogeneous procedure, and the inevitable variability in the chemoprophylactic regimens could affect rates of VTED. Surgeons may use more aggressive regimens for revision cases as these are perceived to have a higher VTED risk based on traditional thinking: thus, VTED rate may be impacted. Variability in weight-bearing status post-operatively affects mobilization, putting patients with restricted weight-bearing at higher risk of VTED. Additionally, there likely exists a cohort of patients with prior VTED who are deemed too high-risk to undergo revision TKA; these patients remain unaccounted for in the current study. Lastly, the data on outcomes in the NSQIP database is limited to 30 days post surgery $[11,18]$.

\section{Conclusion}

Utilizing recent data from nationwide patient cohort and controlling for confounding variables, our results showed that both revision TKA and UKA had a lower risk of
VTED compared to primary TKA, corroborating the results of recent investigations. Additional prospective investigations are needed to explain this unexpected result.

\section{Acknowledgements}

Not applicable

Authors' contributions

AS, DS, and NB all contributed to data collection, data analysis, and manuscript production. All authors read and approved the final manuscript.

\section{Funding}

None

\section{Availability of data and materials}

The data that supports the findings of this study are available from the National Surgical Quality Improvement Program (NSQIP) but restrictions apply to the availability of these data, which were used under license for the current study, and so are not publicly available. Data is, however, available from the authors upon reasonable request and with permission of the NSQIP.

Ethics approval and consent to participate

Not applicable

\section{Consent for publication}

Not applicable

\section{Competing interests}

The authors declare they have no competing interests.

Received: 23 August 2020 Accepted: 22 October 2020

Published online: 04 November 2020

\section{References}

1. Parvizi J, Huang R, Raphael IJ, Arnold WV, Rothman RH (2014) Symptomatic pulmonary embolus after joint arthroplasty: stratification of risk factors. Clin Orthop Relat Res 472(3):903-912. https://doi.org/10.1007/s11999-013-3358-z

2. Parvizi J, Huang R, Raphael IJ, Maltenfort MG, Arnold WV, Rothman RH (2015) Timing of symptomatic pulmonary embolism with warfarin following arthroplasty. J Arthroplast 30(6):1050-1053. https://doi.org/10.1016/j.arth. 2015.01.004

3. Memtsoudis SG, Besculides MC, Gaber L, Liu S, Gonzalez Della Valle A (2009) Risk factors for pulmonary embolism after hip and knee arthroplasty: a population-based study. Int Orthop 33(6):1739-1745. https://doi.org/10. 1007/s00264-008-0659-z

4. Dorr LD, Gendelman V, Maheshwari AV, Boutary M, Wan Z, Long WT (2007) Multimodal thromboprophylaxis for total hip and knee arthroplasty based on risk assessment. J Bone Joint Surg Am 89(12):2648-2657

5. Lieberman JR, Hsu WK (2005) Prevention of venous thromboembolic disease after total hip and knee arthroplasty. J Bone Joint Surg Am 87(9): 2097-2112

6. Park SH, Ahn JH, Park YB, Lee SG, Yim SJ (2016) Incidences of deep vein thrombosis and pulmonary embolism after total knee arthroplasty using a mechanical compression device with and without low-molecular-weight heparin. Knee Surg Relat Res 28(3):213-218. https://doi.org/10.5792/ksrr. 2016.28.3.213

7. Kim NK, Kim TK, Kim JM, Chun CH (2016) Prophylaxis for venous thromboembolism following total knee arthroplasty: a survey of Korean knee surgeons. Knee Surg Relat Res 28(3):207-212. https://doi.org/10.5792/ ksrr.2016.28.3.207

8. American Academy of Orthopaedic Surgeons. Preventing venous thromboembolic disease in patients undergoing elective hip and knee arthroplasty evidence-based guideline and evidence report. https://www. aaos.org/globalassets/quality-and-practice-resources/vte/vte_full_ guideline_10.31.16.pdf. Accessed 13 Sep 2020

9. Eikelboom JW, Karthikeyan G, Fagel N, Hirsh J (2009) American Association of Orthopedic Surgeons and American College of Chest Physicians guidelines for venous thromboembolism prevention in hip and knee arthroplasty differ: what are the implications for clinicians and patients? Chest. 135(2):513-520 
10. Mont MA, Jacobs JJ (2011) AAOS clinical practice guideline: preventing venous thromboembolic disease in patients undergoing elective hip and knee arthroplasty. J Am Acad Orthop Surg 19(12):777-778

11. Courtney PM, Boniello AJ, Levine BR, Sheth NP, Paprosky WG (2017) Are revision hip arthroplasty patients at higher risk for venous thromboembolic events than primary hip arthroplasty patients? J Arthroplast 32(12):37523756

12. Hood BR, Cowen ME, Zheng HT, Hughes RE, Singal B, Hallstrom BR (2019) Association of aspirin with prevention of venous thromboembolism in patients after total knee arthroplasty compared with other anticoagulants: a noninferiority analysis. JAMA Surg 154(1):65-72. https://doi.org/10.1001/ jamasurg.2018.3858

13. Dieterich JD, Fields AC, Moucha CS (2014) Short term outcomes of revision total knee arthroplasty. J Arthroplast 29(11):2163-2166. https://doi.org/10. 1016/j.arth.2014.07.004

14. Lombardi AV, Berend KR, Tucker TL (2007) The incidence and prevention of symptomatic thromboembolic disease following unicompartmental knee arthroplasty. Orthopedics. 30(5 Suppl):46-48

15. Manista GC, Batko BD, Sexton AC et al (2019) Anticoagulation in revision total joint arthroplasty: a retrospective review of 1917 cases. Orthopedics 42(6):323-329. https://doi.org/10.3928/01477447-20190906-02

16. Boylan MR, Perfetti DC, Kapadia BH, Delanois RE, Paulino CB, Mont MA (2017) Venous thromboembolic disease in revision vs primary total knee arthroplasty. J Arthroplast 32(6):1996-1999

17. Shah SS, Satin AM, Mullen JR, Merwin S, Goldin M, Sgaglione NA (2016) Impact of recent quideline changes on aspirin prescribing after knee arthroplasty. J Orthop Surg Res 11(1):123-120. https://doi.org/10.1186/ s13018-016-0456-0

18. American College of Surgeons. American College of Surgeons. Data collection, analysis, and reporting. 2014

19. Duchman KR, Gao Y, Pugely AJ, Martin CT, Callaghan JJ (2014) Differences in short-term complications between unicompartmental and total knee arthroplasty: a propensity score matched analysis. J Bone Joint Surg Am 96(16):1387-1394. https://doi.org/10.2106/JBJS.M.01048

20. Drager J, Hart A, Khalil JA, Zukor DJ, Bergeron SG, Antoniou J (2016) Shorter hospital stay and lower 30-day readmission after unicondylar knee arthroplasty compared to total knee arthroplasty. J Arthroplast 31(2):356361. https://doi.org/10.1016/j.arth.2015.09.014

21. Hansen EN, Ong KL, Lau E, Kurtz SM, Lonner JH (2019) Unicondylar knee arthroplasty has fewer complications but higher revision rates than total knee arthroplasty in a study of large united states databases. J Arthroplast 34(8):1617-1625

22. Bohl DD, Samuel AM, Basques BA, Della Valle CJ, Levine BR, Grauer JN (2016) How much do adverse event rates differ between primary and revision total joint arthroplasty? J Arthroplast 31(3):596-602. https://doi.org/ 10.1016/.j.arth.2015.09.033

23. Brown NM, Sheth NP, Davis K et al (2012) Total knee arthroplasty has higher postoperative morbidity than unicompartmental knee arthroplasty: a multicenter analysis. J Arthroplast 27(8 Suppl):86-90. https://doi.org/10.1016/ j.arth.2012.03.022

24. Kim KT (2018) Unicompartmental knee arthroplasty. Knee Surg Relat Res 30(1):1-2. https://doi.org/10.5792/ksrr.18.014

25. Sun PF, Jia YH (2012) Mobile bearing UKA compared to fixed bearing TKA: a randomized prospective study. Knee 19(2):103-106. https://doi.org/10.1016/j. knee.2011.01.006

26. Berry D, Trousdale R, Dennis D, Paprosky W (2012) Revision total hip and knee arthroplasty. Lippincott Williams \& Wilkins, Philadelphia, p 18

27. Stringer MD, Steadman CA, Hedges AR, Thomas EM, Morley TR, Kakkar W (1989) Deep vein thrombosis after elective knee surgery. an incidence study in 312 patients. J Bone Joint Surg (Br) 71(3):492-497

28. Sloan M, Sheth N, Lee GC (2019) Is obesity associated with increased risk of deep vein thrombosis or pulmonary embolism after hip and knee arthroplasty? A large database study. Clin Orthop Relat Res 477(3):523-532 https://doi.org/10.1097/CORR.0000000000000615

\section{Publisher's Note}

Springer Nature remains neutral with regard to jurisdictional claims in published maps and institutional affiliations.

Ready to submit your research? Choose BMC and benefit from:

- fast, convenient online submission

- thorough peer review by experienced researchers in your field

- rapid publication on acceptance

- support for research data, including large and complex data types

- gold Open Access which fosters wider collaboration and increased citations

- maximum visibility for your research: over $100 \mathrm{M}$ website views per year

At BMC, research is always in progress.

Learn more biomedcentral.com/submissions 